07.2

\title{
Селективные сенсоры двуокиси азота на основе тонких пленок оксида вольфрама при воздействии оптического излучения
}

\author{
(C) А.В. Алмаев, Н.Н. Яковлев, Е.В. Черников, О.П. Толбанов \\ Национальный исследовательский Томский государственный университет, Томск, Россия \\ E-mail: almaev_alex@mail.ru
}

Поступило в Редакцию 3 июня 2019г.

В окончательной редакции 24 июня 2019г.

Принято к публикации 26 июня 2019г.

\begin{abstract}
Показана возможность селективного детектирования $\mathrm{NO}_{2}$ в воздухе начиная с концентрации $1 \mathrm{ppm}$ сенсорами на основе тонких пленок $\mathrm{Au} / \mathrm{WO}_{3}: \mathrm{Au}$ при замене постоянного нагрева облучением диодом с длиной волны максимума интенсивности излучения $400 \mathrm{~nm}$. Активация облучением фотодесорбции на порядок снижает времена отклика сенсоров при воздействии $\mathrm{NO}_{2}$. Установлено, что воздействие высокой влажности в условиях облучения сенсоров при комнатной температуре приводит к повышению отклика на $\mathrm{NO}_{2}$ за счет появления дополнительных центров адсорбции. Отсутствие отклика сенсоров на восстановительные газы и изменение концентрации кислорода в газовой смеси вызвано фотодесорбцией хемосорбированных частиц $\mathrm{O}_{2}^{-}$при взаимодействии с генерируемыми при собственных переходах дырками в приповерхностной части $\mathrm{WO}_{3}$.
\end{abstract}

Ключевые слова: оксид вольфрама, двуокись азота, тонкие пленки, магнетронное распыление, оптическое излучение.

DOI: 10.21883/PJTF.2019.20.48384.17901

Интерес к разработке сенсоров низких концентраций $\mathrm{NO}_{2}$ обусловлен необходимостью экологического мониторинга воздуха городов. Согласно санитарным нормам, предельная допустимая концентрация (ПДК) $\mathrm{NO}_{2}$ рабочей зоны - 1 ppm. В качестве чувствительных элементов сенсоров перспективно использовать тонкие пленки $\mathrm{WO}_{3}$ [1-3]. Принцип работы сенсоров основан на хемосорбционном увеличении сопротивления полупроводника при воздействии $\mathrm{NO}_{2}$. Сенсоры на основе $\mathrm{WO}_{3}$ обладают относительно высокой потребляемой мощностью (300-1000 mW), обусловленной необходимостью нагрева полупроводника до высоких температур $\left(200-500^{\circ} \mathrm{C}\right)$ для стимулирования реакций на его поверхности. Даже при нагреве сенсоры характеризуются большими временами отклика (порядка сотен секунд) [1-3].

Для повышения быстродействия и увеличения отклика сенсоров $\mathrm{WO}_{3}$ модифицируют добавками $\mathrm{Au}$ в объеме и на поверхности [1-3]. Аu на поверхности $\mathrm{WO}_{3}$ приводит к ускорению реакций между адсорбентом и адсорбатом за счет каталитических свойств. Согласно структурным исследованиям, введение $\mathrm{Au}$ в объем пленок $\mathrm{WO}_{3}$ приводит к образованию различных фаз $\mathrm{WO}_{3}$, что вызывает увеличение количества неоднородностей на поверхности полупроводника, являющихся центрами адсорбции для $\mathrm{NO}_{2}$. Добавки $\mathrm{Au}$ позволяют снизить время отклика до 60-120s при воздействии $\mathrm{NO}_{2}$, однако рабочая температура в этом случае составляет не менее $230-250^{\circ} \mathrm{C}$, а детектируемые концентрации газа превышают ПДК [1-3].

Альтернативой нагреву сенсоров на основе $\mathrm{WO}_{3}$ служит облучение оптическим излучением. Эффект влия- ния оптического облучения на газочувствительные свойства металлооксидных полупроводников наблюдается при собственных оптических переходах [4-7]. Следует отметить, что ширина запрещенной зоны $E_{g}$ пленок $\mathrm{WO}_{3}$ составляет 2.7-3.3 eV [8] и зависит от многих факторов. Под изменениями газочувствительных свойств сенсоров при облучении понимается увеличение/проявление отклика на $\mathrm{NO}_{2}$ в отсутствие нагрева, а также снижение времен отклика и восстановления. В случае $\mathrm{WO}_{3}$ чаще всего используются источники оптического излучения с длиной волны, близкой к $400 \mathrm{~nm}[5,6]$. При увеличении мощности излучения отклик на $\mathrm{NO}_{2}$ сенсоров на основе $\mathrm{WO}_{3}$ падает за счет усиления фотодесорбции [5]. Поэтому для улучшения газочувствительных свойств целесообразнее сенсоры подвергать облучению с плотностью мощности менее $25 \mathrm{~mW} / \mathrm{cm}^{2}$. Модификация $\mathrm{WO}_{3}$ золотом повышает отклик на воздействие $\mathrm{NO}_{2}$ и при облучении в отсутствие нагрева [6].

В работах $[9,10]$ описана возможность детектирования низких концентраций $\mathrm{NO}_{2}$ при замене нагрева облучением зеленым светодиодом сенсоров на основе толстых пленок $\mathrm{ZnO}, \mathrm{SnO}_{2}$ и $\mathrm{In}_{2} \mathrm{O}_{3}$, модифицированных квантовыми точками $\mathrm{CdSe}$. Такие структуры при облучении не отличаются селективностью и характеризуются временами отклика порядка 10 min при воздействии $\mathrm{NO}_{2}$ в диапазоне концентраций $0.1-5.0$ ppm.

Кроме того, воздействие оптического облучения, стимулирующего собственные переходы, приводит к улучшению газочувствительных свойств сенсоров восстановительных газов на основе тонких пленок $\mathrm{SnO}_{2}: \mathrm{Si}$ [7]. В этом случае под улучшением газочувствительных 
свойств понималось снижение рабочей температуры сенсоров в 2-3 раза и увеличение отклика.

На основе анализа литературы можно отметить отсутствие исследований селективности сенсоров, влияния влажности на их газочувствительные свойства при облучении в отсутствие нагрева, а также исследований повторяемости результатов. Практически не установлены механизмы влияния облучения на газочувствительные свойства $\mathrm{WO}_{3}$. Настоящая работа направлена на исследование данных вопросов.

Пленки $\mathrm{WO}_{3}$ были получены высокочастотным магнетронным распылением оксидной мишени, на поверхности которой были закреплены кусочки Au. Подложкой служили пластины сапфира. Контакты к чувствительному слою и нагреватель на обратной стороне подложки формировались путем напыления платины до нанесения $\mathrm{WO}_{3}$. Дисперсные слои $\mathrm{Au}$ на поверхность $\mathrm{WO}_{3}$ наносились магнетронным распылением на постоянном токе. Все изготовленные пластины подвергались стабилизирующему отжигу в атмосфере воздуха при $500^{\circ} \mathrm{C}$ в течение $4 \mathrm{~h}$. Толщина пленок $\mathrm{WO}_{3}$ составляла 95-105 nm. При помощи рентгенодифракционного анализа установлено, что в исследуемых образцах проявляются $\beta$-, $\alpha$ - и $\gamma$-фазы $\mathrm{WO}_{3}$, содержание которых составляет 71.8, 1.5 и 26 vol.\% соответственно. Концентрация $\mathrm{Au}$ в пленках 0.7 vol.\%. Размеры зерен $\mathrm{WO}_{3}$, определенные при помощи атомно-силовой и сканирующей электронной микроскопий, составляют 11-37 nm. Частицы металлического золота сегрегируют на поверхности пленки и обладают размером от 9 до $15 \mathrm{~nm}$.

Для измерения временни́х зависимостей сопротивления сенсоров использовалась установка, состоящая из металлической камеры, в которую помещались образцы и датчик влажности. Через камеру прокачивалась смесь газов $\mathrm{N}_{2}, \mathrm{O}_{2}$ и $\mathrm{NO}_{2}$, полученная при помощи генератора газовых смесей. В качестве чистого воздуха принималась смесь азота и кислорода с концентрацией $\mathrm{O}_{2} 21$ vol.\%. Сопротивление датчиков измерялось при помощи источника-измерителя Keithley 2636A. Для нагрева сенсоров использовался лабораторный источник постоянного тока.

Облучение сенсоров проводилось излучающими диодами марки L-7104UVC, которые находились на расстоянии $\sim 2 \mathrm{~mm}$ от чувствительного слоя. Диапазон длин волн излучаемого диодом света составлял $370-430 \mathrm{~nm}$. Длина волны максимума интенсивности излучения диодов $400 \mathrm{~nm}$. Плотность мощности излучения, падающего на $\mathrm{WO}_{3}$, составляла $15 \mathrm{~mW} / \mathrm{cm}^{2}$. Питание диодов осуществлялось лабораторным источником постоянного тока. Потребляемая диодами мощность составляла $60 \mathrm{~mW}$. Воздействие $\mathrm{NO}_{2}$ на сенсоры осуществлялось после установления стационарного сопротивления пленки $\mathrm{WO}_{3}$ при облучении диодом. На основе анализа спектров поглощения оптического излучения $\mathrm{Au} / \mathrm{WO}_{3}: \mathrm{Au}$ получено значение $E_{g}$, соответствующее $3.0-3.2 \mathrm{eV}$. Из этого следует, что облучение используемым диодом вызывает собственные переходы в $\mathrm{WO}_{3}$.

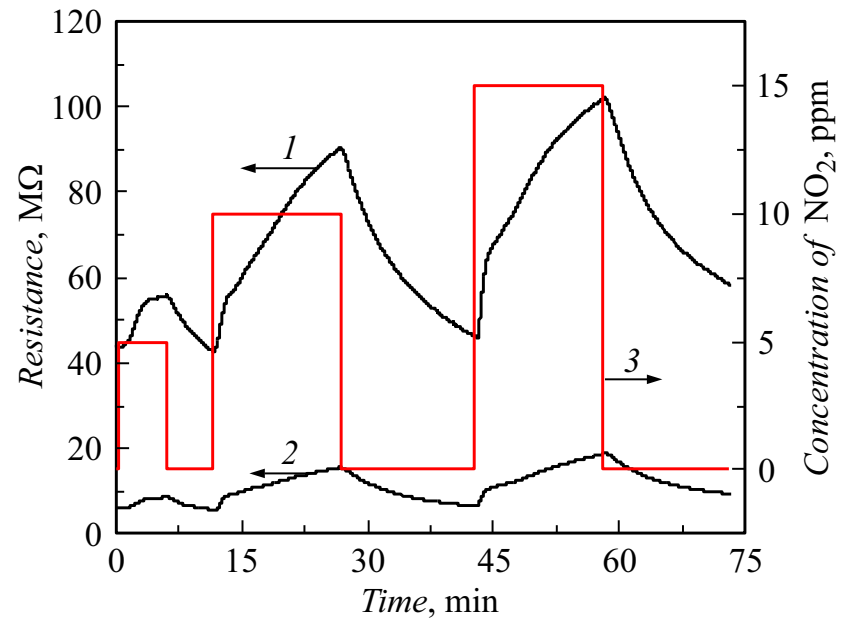

Временнб́е зависимости сопротивления состаренного (1) и нового (2) сенсоров при облучении и воздействии 5,10 и $15 \mathrm{ppm}$ $\mathrm{NO}_{2}$, а также изменение концентрации газа в измерительной камере при увеличении времени эксперимента (3).

Измерения сопротивления сенсоров после предварительного прогрева показали, что в отсутствие облучения отклик при воздействии 5 ppm $\mathrm{NO}_{2}$ в 1.5-2 раза меньше, чем в условиях с засветкой. Для того чтобы началось возрастание сопротивления $R$ сенсоров при воздействии $\mathrm{NO}_{2}$ и выключенном облучении, должно пройти значительное время ( $10 \mathrm{~min})$. Влияние установки задания газовых смесей исключается, так как практически сразу после подачи $\mathrm{NO}_{2}$ начинает возрастать $R$ облучаемых сенсоров. В качестве времени отклика сенсоров при воздействии 5 ppm $\mathrm{NO}_{2}$ ввиду малого изменения сопротивления был выбран временной промежуток, за который $R$ сенсоров достигнет уровня $R_{0 l}+0.9\left(R_{1 l}-R_{0 l}\right)$, где $R_{0 l}$ - стационарное сопротивление облучаемых сенсоров в чистом воздухе, $R_{1 l}$ - стационарное сопротивление облучаемых сенсоров при воздействии $\mathrm{NO}_{2}$. Время отклика, определенное таким способом при включении облучения и комнатной температуре, составляет $120 \mathrm{~s}$, а при выключенном облучении - $12 \mathrm{~min}$.

На рисунке показаны временны́е зависимости $R$ сенсоров при облучении и воздействии 5, 10 и $15 \mathrm{ppm}$ $\mathrm{NO}_{2}$. Начиная с концентрации $\mathrm{NO}_{2}$, равной $10 \mathrm{ppm}$, сопротивление $\mathrm{WO}_{3}$ при воздействии газа не стабилизируется. В ходе эксперимента установлено значительное влияние предыстории сенсоров на сопротивление и отклик, особенно в условиях облучения. При прогреве сенсоров их сопротивления совпадают. Образцы, прошедшие испытания в течение месяца при комнатной температуре и в условиях облучения, характеризуются сопротивлением на порядок бо́льшим, чем $R$ новых образцов. Отклик новых сенсоров примерно в $1.3-1.5$ раза больше отклика образцов, прошедших испытания. После месяца испытаний характеристики сенсоров стабилизируются. В качестве отклика в данных условиях было выбрано отношение $R_{1 l} / R_{0 l}$, где в качестве $R_{1 l}$ 
выбиралось максимальное значение сопротивления при воздействии $\mathrm{NO}_{2}$.

Минимальная используемая в экспериментах концентрация $\mathrm{NO}_{2}-1 \mathrm{ppm}-$ соответствует ПДК. Отклик при воздействии этой концентрации в условиях облучения и отсутствия нагрева составил 1.2, а время отклика - $85 \mathrm{~s}$. При выключенном облучении сенсоры не реагируют на воздействие такой малой концентрации $\mathrm{NO}_{2}$.

Эксперимент при многократной подаче концентрации $\mathrm{NO}_{2} 5$ ppm с последующей прокачкой через измерительную камеру чистого воздуха показал, что с каждым новым циклом подачи газа отклик снижается, но после каждой откачки $\mathrm{NO}_{2} R_{0 l}$ восстанавливается. Отклик падает за счет снижения $R_{1 l}$. Причиной этого служат устойчивые продукты реакций между молекулами $\mathrm{NO}_{2}$ и поверхностью $\mathrm{WO}_{3}$, для десорбции которых после каждого воздействия газа нужен прогрев при температуре $400^{\circ} \mathrm{C}$ в течение $10-30 \mathrm{~s}$.

Воздействие $150 \mathrm{ppm} \mathrm{H}_{2}$ и $\mathrm{CO}$ и изменение концентрации $\mathrm{O}_{2}$ в камере на \pm 5 vol.\% не влияет на $R$ сенсоров в условиях облучения при комнатной температуре. При переходе от нулевой относительной влажности к 76\% сопротивление $\mathrm{WO}_{3}$ уменьшается в 2.9 раза, а отклик на $\mathrm{NO}_{2}$ возрастает в 1.2 раза. Известно, что чувствительность сенсоров к восстановительным газам обусловлена их взаимодействием с ранее хемосорбированным кислородом. После предварительного прогрева сенсоров в отсутствие облучения бо́льшая часть объема кристаллов $\mathrm{WO}_{3}$ обеднена электронами. На поверхности пленок $\mathrm{WO}_{3}$, который является полупроводником $n$-типа проводимости, хемосорбирован кислород в форме $\mathrm{O}_{2}^{-}$, соответствующей низким температурам. Хемосорбции $\mathrm{O}_{2}$ активно способствует Аu. При включении излучения в приповерхностной части кристаллов $\mathrm{WO}_{3}$ генерируются избыточные электроны и дырки. Согласно направлению поля в области пространственного заряда, электроны уходят в объем зерен $\mathrm{WO}_{3}$, а дырки - на поверхность, где происходит реакция

$$
\mathrm{O}_{2}^{-}+h^{+} \leftrightarrow \mathrm{O}_{2}^{0}+S
$$

В реакции (1) введены следующие обозначения: $h^{+}-$ дырка, $S$ - свободный центр адсорбции на поверхности $\mathrm{WO}_{3}$. Сопротивление сенсоров при облучении падает за счет генерации избыточных носителей заряда и десорбции кислорода. Таким образом, поверхность $\mathrm{WO}_{3}$ очищается от хемосорбированного $\mathrm{O}_{2}^{-}$и исчезают центры адсорбции для $\mathrm{H}_{2}$ и СО. Молекулы $\mathrm{NO}_{2}$ взаимодействуют с поверхностью $\mathrm{WO}_{3}$ следующим образом:

$$
\mathrm{NO}_{2}(\text { gas })+e^{-}+S \leftrightarrow \mathrm{NO}_{2}^{-}(a d s)
$$

C учетом низкой температуры термодесорбция $\mathrm{H}_{2} \mathrm{O}$ невозможна. Однако энергии излучения хватает для фотодесорбции части молекул воды

$$
\mathrm{H}_{2} \mathrm{O}+h v \rightarrow \mathrm{H}^{+}+\mathrm{OH}^{-} .
$$

Появившиеся в результате реакции (3) ОН-группы реагируют на поверхности с дырками и десорбируются, a $\mathrm{H}^{+}$взаимодействует с устойчивым кислородом $\mathrm{O}_{2}^{-}$, который еще не десорбировался согласно реакции (1) с дырками. Это процесс описывается реакцией

$$
2 \mathrm{H}^{+}+\mathrm{O}_{2}^{-} \rightarrow 2 \mathrm{OH}^{0}+S .
$$

В результате этого взаимодействия появляются дополнительные $S$, что приводит к увеличению отклика сенсоров на $\mathrm{NO}_{2}$ при высокой влажности. В реакциях (1) и (4) десорбции нейтральных частиц способствует облучение. Фотодесорбцией также объясняется уменьшение времени отклика сенсоров при облучении. Положительная реакция на $\mathrm{H}^{+}$и отсутствие отклика сенсоров на $\mathrm{H}_{2}$ объясняются тем, что концентрация $\mathrm{H}^{+}$может на два порядка превышать используемую в эксперименте концентрацию $\mathrm{H}_{2}$.

Таким образом, для детектирования $\mathrm{NO}_{2}$ в воздухе начиная с концентрации 1 ppm при помощи сенсоров на основе тонких пленок $\mathrm{Au} / \mathrm{WO}_{3}$ : $\mathrm{Au}$ постоянный нагрев можно заменить облучением диодом с максимумом интенсивности излучения на длине волны $400 \mathrm{~nm}$. Потребляемая мощность диода $60 \mathrm{~mW}$. После каждого воздействия $\mathrm{NO}_{2}$ на сенсор необходим прогрев при температуре $400^{\circ} \mathrm{C}$ в течение $10-30 \mathrm{~s}$. При облучении диодом значительно сокращается время отклика сенсоров, что обусловлено активацией центров фотодесорбции. Облучаемые сенсоры в отсутствие нагрева не демонстрируют чувствительности к $\mathrm{H}_{2}, \mathrm{CO}$ и к изменению содержания $\mathrm{O}_{2}$ в газовой смеси. Образовавшиеся в ходе собственных переходов дырки способствуют десорбции $\mathrm{O}_{2}$, а на появившиеся свободные центры адсорбируется только $\mathrm{NO}_{2}$. Высокая влажность способствует увеличению отклика сенсоров на $\mathrm{NO}_{2}$ в условиях облучения и отсутствия нагрева за счет освобождения дополнительных центров адсорбции для этого газа.

\section{Конфликт интересов}

Авторы заявляют, что у них нет конфликта интересов.

\section{Список литературы}

[1] Анисимов О.В., Гаман В.И., Максимова Н.К., Найден Ю.П., Новиков В.А., Севастьянов Е.Ю., Рудов Ф.В., Черников Е.В. // ФТП. 2010. Т. 44. В. 3. С. 383-389. doi.org/10.1134/S1063782610030164

[2] Анисимов О.В., Максимова Н.К., Найден Ю.П., Новиков В.А., Севастьянов Е.Ю., Рудов Ф.В., Черников Е.В. // ЖФХ. 2010. Т. 84. В. 7. С. 1345-1350. doi.org/10.1134/S003602441007023X

[3] Kabcum S., Kotchasak N., Channei D., Tuantranont A., Wisitsoraat A., Phanichphant S., Liewhiran C. // Sensors Actuators B. 2017. V. 252. P. 523-536. doi.org/10.1016/j.snb.2017.06.011

[4] Волькенштейн Ф.Ф. Электронные процессы на поверхности полупроводников при хемосорбции. М.: Наука, 1987. $432 \mathrm{c}$. 
[5] Saidi T., Palmowski D., Babicz-Kiewlicz S., Welearegay T.G., El Bari N., Ionescu R., Smulko J., Bouchikhi B. // Sensors Actuators B. 2018. V. 273. P. 1719-1729. doi.org/10.1016/j.snb.2018.07.098

[6] Espid E., Noce A.S., Taghipour F. // J. Photochem. Photobiol. A. 2019. V. 374. P. $95-105$. doi.org/10.1016/j.jphotochem.2019.01.038

[7] Рембеза С.И., Свистова Т.В., Кошелева Н.Н., Овсянников С.В., Аль Тамееми В.М.К. // Письма в ЖТФ. 2015. T. 41. B. 23. C. 32-39. doi.org/10.1134/S1063785015120135

[8] González-Borrero P.P., Sato F., Medina A.N., Baesso M.L., Bento A.C., Baldissera G., Persson C., Niklasson G.A., Granqvist C.G., Ferreira da Silva A. // Appl. Phys. Lett. 2010. V. 96. P. 061909 (1-3). doi.org/10.1063/1.3313945

[9] Chizhov A.S., Rumyantseva M.N., Vasiliev R.B., Filatova D.G., Drozdov K.A., Krylov I.V., Marchevsky A.V., Karakulina O.M., Abakumov A.M., Gaskov A.M. // Thin Solid Films. 2016. V. 618. P. 253-262. doi.org/10.1016/j.tsf.2016.09.029

[10] Чижов А.С., Мордвинова Н.Е., Румянцева М.Н., Крылов И.В., Дроздов К.A., Li X., Гаськов А.М. // ЖНХ. 2018. T. 63. B. 4. C. 480-486. doi.org/10.1134/S0036023618040071 